\title{
Psychological Wellbeing of Parents with Infants Admitted to the Neonatal Intensive Care Unit during SARS-CoV-2 Pandemic
}

\author{
Laura Polloni $^{1}$, Francesco Cavallin ${ }^{2}$ (D) Elisabetta Lolli ${ }^{3}$, Rossana Schiavo ${ }^{1}$, Martina Bua ${ }^{1}$, Biancarosa Volpe ${ }^{1}$, \\ Marta Meneghelli ${ }^{3}$, Eugenio Baraldi ${ }^{3}$ and Daniele Trevisanuto ${ }^{3, *}$ \\ 1 Psychology Unit, University Hospital of Padua, 35128 Padua, Italy; laura.polloni@aopd.veneto.it (L.P.); \\ rossana.schiavo@aopd.veneto.it (R.S.); martina.bua@aopd.veneto.it (M.B.); biancarosa.volpe@unipd.it (B.V.) \\ 2 Independent Statistician, 36020 Solagna, Italy; cescocava@libero.it \\ 3 Neonatal Intensive Care Unit, Department of Women's and Children's Health, University Hospital of Padua, \\ Via Giustiniani, 3, 35128 Padua, Italy; elisabetta.lolli@aopd.veneto.it (E.L.); \\ meneghelli.marta@aopd.veneto.it (M.M.); eugenio.baraldi@unipd.it (E.B.) \\ * Correspondence: daniele.trevisanuto@unipd.it
}

\section{check for} updates

Citation: Polloni, L.; Cavallin, F.; Lolli, E.; Schiavo, R.; Bua, M.; Volpe, B.; Meneghelli, M.; Baraldi, E.; Trevisanuto, D. Psychological Wellbeing of Parents with Infants Admitted to the Neonatal Intensive Care Unit during SARS-CoV-2 Pandemic. Children 2021, 8, 755 . https://doi.org/10.3390/ children 8090755

Academic Editor: Mikko Hallman

Received: 6 August 2021

Accepted: 26 August 2021

Published: 30 August 2021

Publisher's Note: MDPI stays neutral with regard to jurisdictional claims in published maps and institutional affiliations.

Copyright: (C) 2021 by the authors. Licensee MDPI, Basel, Switzerland. This article is an open access article distributed under the terms and conditions of the Creative Commons Attribution (CC BY) license (https:/ / creativecommons.org/licenses/by/ $4.0 /)$.

\begin{abstract}
The current SARS-CoV-2 disease (COVID-19) pandemic is a sudden major stressor superimposed on pre-existing high distress in parents of infants admitted to the neonatal intensive care unit (NICU). This study aimed to investigate the psychological wellbeing of NICU parents during the COVID-19 pandemic. Forty-four parents of 25 inpatients of the Padua University Hospital NICU were included from June 2020 to February 2021. At 7-14 days postpartum parents completed the Edinburgh Postnatal Depression Scale (EPDS), State-Trait Anxiety Inventory (STAI), Parental Stressor Scale: NICU (PSS:NICU) and an ad-hoc questionnaire measuring parental COVID-19 related stress. About one third of parents reported extreme/high stress and a relevant negative impact on parenthood experience. Less time (82\%) and less physical contact $(73 \%)$ with infants due to COVID-19 preventive measures were the most frequent negative factors. Higher COVID-19 related parental stress was positively associated with anxiety, depression, NICU parental stress, stress related to NICU environment, and parental role alterations. Depression symptoms, stress related to infant condition and parental role alterations were higher in mothers. The pandemic affected parental emotional and relational wellbeing directly through additional stress due to COVID-19 concerns and indirectly through the impact of restrictions on the experience of becoming parents.
\end{abstract}

Keywords: anxiety; depression; fathers; mothers; preterm child; stress

\section{Introduction}

From a psychological perspective, parents of infants admitted to the neonatal intensive care unit (NICU) are a vulnerable population, as they experience trauma (due to critical birth and separation from their infants) and stress (regarding medical conditions and related interventions) [1-3]. Parents report feelings of guilt, shame and high levels of stress, mood, and anxiety symptoms [1,4]. This is associated with an elevated risk for subsequent impaired child development and poorer family functioning [5-9]. A multi-layered approach to support parents in the NICU with particular attention to mental health has been recently highlighted $[10,11]$. In this context, the current corona virus disease (COVID-19) pandemic caused by the SARS-CoV-2 virus acts as a sudden, new-onset major environmental stressor superimposed on pre-existing high levels of NICU family psychological distress [3,12].

As the COVID-19 pandemic spread dangerously in Italy and worldwide, several infection preventive measures were adopted, including limitations for hospital visitors, especially in the wards with the most vulnerable patients. This forced NICU healthcare providers and parents to face severe limitations in visitation policies, challenging familycentered developmental care practices. This, in turn, may affect the ability for parents to 
cope with pandemic-related stress, thereby exacerbating the stress of having an infant in the NICU, and further hampering their confidence as primary caregivers [3,12-14].

Restrictions of visitation all together would undoubtedly add to the parental stress of NICU admission. Information on the psychological status of parents with infants admitted to a NICU during the COVID-19 pandemic is lacking. A preliminary qualitative study reported dysphoric emotions in the ten parents considered, and highlighted that restrictions accentuated the emotional and relational suffering of NICU families [13]. One of the COVID-19 preventive measures adopted at our Institution was limiting access to the NICU to one parent per baby, one hour per day. In our country, restrictions to parental visits in NICU were broadly applied but were not uniformly mandatory, thus each hospital followed local protocols and indications of the hospital directorate. Some of the NICU staff at our institution did not agree with the restrictions but could not oppose to the implementation. While strict restrictions on parental visits were initially adopted to prevent infection spread in the NICU, recent position statements indicate to relax such restrictions to favor parent-infant contact $[15,16]$. During the period of visit limitations, a screening of parents' psychological wellbeing has been performed in order to identify parents in need of support. Understanding and accommodating psychological needs of NICU families seems crucial in efficiently caring for vulnerable infants in this critical historical period. This study aimed to investigate the psychological wellbeing of parents with infants admitted to the NICU during the COVID-19 pandemic. A secondary objective was to analyze the possible differences between mothers and fathers.

\section{Materials and Methods}

\subsection{Study Design}

This is an observational study on the psychological wellbeing of mothers and fathers with infants admitted to NICU after birth during the COVID-19 pandemic. The study was performed in accordance with the European regulation regarding potential sensitive data and has been approved by the Padua University Hospital Ethics Committee (protocol number 0014664). All parents gave their written consent to use the data for scientific purposes.

\subsection{Participants}

Parents of infants admitted to the NICU of the Padua Hospital during COVID-19 pandemic were eligible for inclusion. We excluded (i) parents of infants with congenital malformations or major complications, (ii) parents who suffered from a major mental illness, (iii) parents who did not understand the Italian language, and (iv) drug-user/addict mothers. Parents were included consecutively from June 2020 to February 2021. The participants were not compensated for participating in this study.

Prior to the pandemic, both parents were allowed to visit infants admitted to the NICU at the same time and without time restrictions (24/24 h). During the pandemic, access to the NICU was limited to one parent per baby, one hour per day. Such restrictions on parental visits lasted throughout the study period.

\subsection{Data Collection}

Parents were asked to complete the following questionnaires at 7-14 days postpartum. This time interval is consistent with previous studies [2,17-19] and EPDS instructions for administration:

(1) The Edinburgh Postnatal Depression Scale (EPDS) [20,21] aims to identify depressive symptoms in women who have recently given birth. The tools have also been effectively used with fathers [2]. Individuals who score 13 or more are considered at risk of developing depression [20].

(2) The State-Trait Anxiety Inventory (STAI) [22] measures symptoms of anxiety in adults. It consists of two sub-scales of 20 items respectively evaluating "state anxiety" (STAI-S anxiety in a specific situation) and "trait anxiety" (STAI-T anxiety as a general trait). 
Each item is based on four levels of response. A score from 40 to 50 indicates mild anxiety, 51 to 60 moderate anxiety, and $>60$ severe anxiety.

(3) The Parental Stressor Scale: NICU (PSS: NICU) $[23,24]$ measures stress experienced by parents during hospitalization related to parental role alteration (PRA), infant behavior and appearance (IBA), and sights and sounds of the unit (SS). Parents are asked to rate items on a five-point scale ranging from 1 (not at all stressful) to 5 (extremely stressful). An item on perceived overall parental stress is also present.

(4) An ad hoc questionnaire has been developed to assess the COVID-19 related parental stress. The tool, shown in Supplementary Table S1, consists of two items asking to be answered on a Likert scale from 1 (not at all) to 5 (extremely) and one item considering the presence or absence of 10 stress factors plus an additional one that the respondents can express (other). The instrument focuses on the impact of the COVID-19 pandemic, in terms of stress, on the experience of becoming parent. The questions were designed based on the literature $[25,26]$ and clinical experience. The score ranges from 2 to 21 . Socio-demographic and clinical data were collected through a crosscheck between parents' reports and medical records.

\subsection{Statistical Analysis}

Data were summarized as median and interquartile range (continuous data) or frequency and percentage (categorical data). Associations between continuous variables were assessed using Spearman's rank correlation coefficient (r). Comparisons of continuous variables among groups were performed using the Mann-Whitney test and Kruskal-Wallis test. In the sub-analysis of mother-father pairs of the same child, continuous variables were compared in mother-father matched pairs using Wilcoxon signed rank test. All tests were two-sided and a $p$-value less than 0.05 was considered significant. Statistical analysis was performed using R 4.0 (R Foundation for Statistical Computing, Vienna, Austria) [27].

\section{Results}

During the study period, 277 newborn infants were admitted to the NICU. The parents of 113 infants were excluded because the infants had congenital malformations $(n=17)$ or were discharged within 8 days of life $(n=96)$. The parents of 117 infants were excluded because they did not understand the Italian language $(n=72)$ or refused to participate $(n=45)$. Finally, parents of 22 infants could not be contacted because the researcher was not available.

The analyses include 44 parents (19 mother-father pairs and six mothers) of 25 infants (median gestational age 34 weeks, IQR 31-35). Parental and neonatal characteristics are reported in Table 1.

COVID-19 related parental stress is displayed in Figure 1. Thirteen parents (30\%) indicated the COVID-19 pandemic as an extreme/high source of stress, and 15 parents (34\%) acknowledged a relevant negative impact of the COVID-19 pandemic on the experience of becoming parents. Less time $(82 \%)$ and less physical contact $(73 \%)$ with the infant due to preventive measures, and additional concerns about the infant's health $(57 \%)$ were the most frequent negative factors. Less support from family/friends due to preventive measures $(41 \%)$, concerns about family / friends' health $(39 \%)$ and loneliness $(32 \%)$ were also frequently reported. The median score on COVID-19 related parental stress was 10 out of 21 (IQR 8-12) (Supplementary Table S2). 
Table 1. Parental and neonatal characteristics.

\begin{tabular}{|c|c|c|}
\hline & Variable & N (\%) or Median (IQR) \\
\hline \multirow{16}{*}{ Parents $(n=44)$} & $\begin{array}{l}\text { Parent: } \\
\text { Mothers } \\
\text { Father }\end{array}$ & $\begin{array}{l}25(67) \\
19(43)\end{array}$ \\
\hline & Age, years & $35(32-39)$ \\
\hline & $\begin{array}{l}\text { Education level: } \\
\text { Primary or middle school } \\
\text { High school } \\
\text { University }\end{array}$ & $\begin{array}{l}12(27) \\
18(41) \\
14(32)\end{array}$ \\
\hline & $\begin{array}{l}\text { Number of pregnancies: } \\
\text { One pregnancy } \\
\text { Two pregnancies }\end{array}$ & $\begin{array}{l}28(64) \\
16(36)\end{array}$ \\
\hline & Visits to the infant in the NICU, $\mathrm{n}$ & $8(5-14)$ \\
\hline & STAI state & $42(37-51)$ \\
\hline & $\begin{array}{l}\text { STAI state: } \\
<40 \\
40-50 \\
51-60 \\
>60\end{array}$ & $\begin{array}{l}20(46) \\
12(27) \\
8(18) \\
4(9)\end{array}$ \\
\hline & STAI trait & $40(35-46)$ \\
\hline & $\begin{array}{l}\text { STAI trait: } \\
<40 \\
40-50 \\
51-60 \\
>60\end{array}$ & $\begin{array}{l}22(50) \\
18(41) \\
3(7) \\
1(2)\end{array}$ \\
\hline & EPDS & $9(7-12)$ \\
\hline & EPDS $\geq 13$ & $10(23)$ \\
\hline & PSS-SS & $1.7(1.5-2.4)$ \\
\hline & PSS-IBA & $1.7(1.4-2.3)$ \\
\hline & PSS-PRA & $2.9(2.3-3.7)$ \\
\hline & PSS-perceived stress item & $3(3-4)$ \\
\hline & PSS-total score & $2.2(1.8-2.7)$ \\
\hline \multirow{3}{*}{ Infants $(\mathrm{n}=25)$} & Gestational age, weeks & $34(31-35)$ \\
\hline & Birth weight, grams & $2185(1480-3100)$ \\
\hline & Age at parental psychological screening, days & $13(8-14)$ \\
\hline \multirow{3}{*}{$\begin{array}{l}\text { Perinatal } \\
\text { information } \\
(n=25)\end{array}$} & $\begin{array}{l}\text { Conception: } \\
\text { Spontaneous } \\
\text { Medically assisted }\end{array}$ & $\begin{array}{l}20(80) \\
5(20)\end{array}$ \\
\hline & $\begin{array}{l}\text { Pregnancy: } \\
\text { Singleton } \\
\text { Twin }\end{array}$ & $\begin{array}{l}22(88) \\
3(12)\end{array}$ \\
\hline & $\begin{array}{l}\text { Delivery: } \\
\text { Vaginal or elective caesarean } \\
\text { Emergency caesarean }\end{array}$ & $\begin{array}{l}6(24) \\
19(76)\end{array}$ \\
\hline $\begin{array}{l}\text { Diagnosis at } \\
\text { discharge }(n=25)\end{array}$ & $\begin{array}{l}\text { RDS + prematurity } \\
\text { Sepsis } \\
\text { Asphixia } \\
\text { Prematurity } \\
\text { RDS }\end{array}$ & $\begin{array}{l}16(64) \\
3(12) \\
2(8) \\
2(8) \\
2(8)\end{array}$ \\
\hline
\end{tabular}

EPDS: Edinburgh Postnatal Depression Scale. IBA: infant behavior and appearance. PRA: parental role alteration (PRA). PSS: parental stressor scale. SS: sights and sounds of the unit. STAI: State-Trait Anxiety Inventory. 


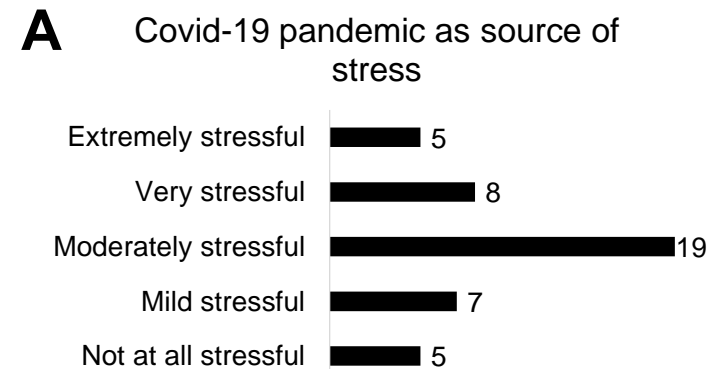

B Negative impact of Covid-19 pandemic on becoming parent

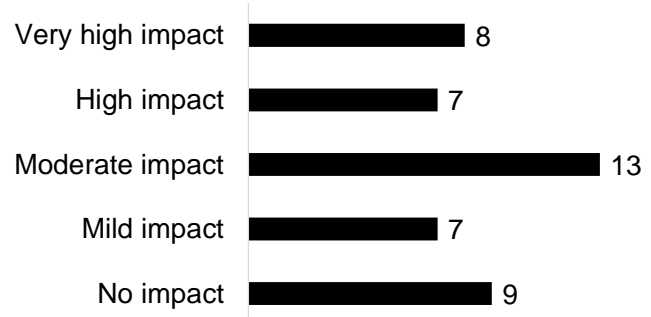

C Covid-19 related factors having a negative impact on becoming parent

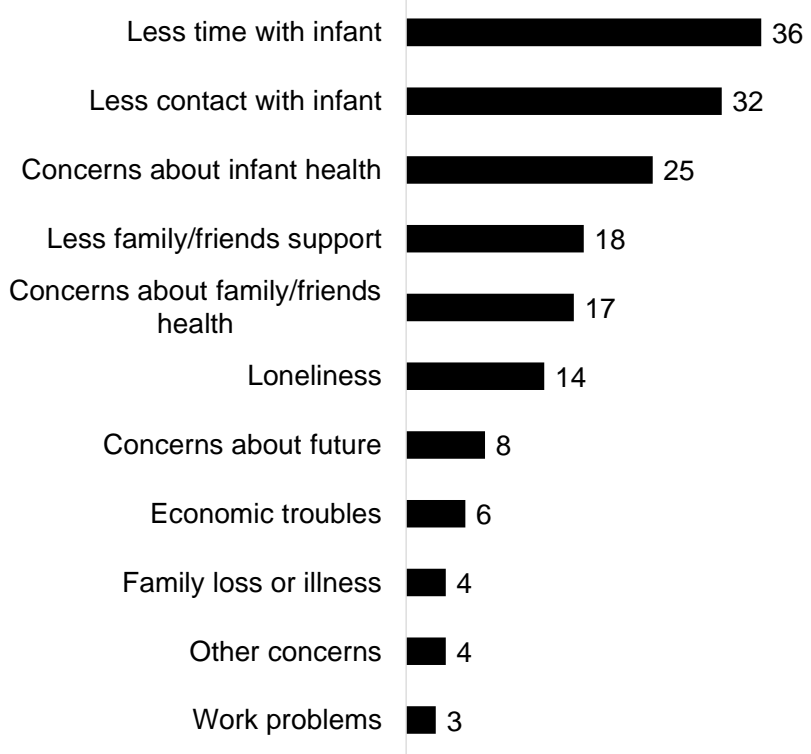

Figure 1. COVID-19 related parental stress: COVID-19 as source of stress (A), negative impact of COVID-19 on becoming a parent (B) and COVID-19 related factors having a negative impact on becoming a parent (C).

Higher COVID-19 related parental stress was associated with a higher STAI state $(\mathrm{r}=0.44, p=0.003)$, higher STAI trait $(\mathrm{r}=0.46, p=0.002)$, higher EPDS $(\mathrm{r}=0.35, p=0.02)$, higher PSS-SS $(r=0.34, p=0.02)$, higher PSS-PRA $(r=0.38, p=0.01)$ and higher PSS-total score $(r=0.38, p=0.01)$ (Figure 2). PSS-perceived stress item was also associated with COVID-19 related parental stress $\left(\mathrm{r}_{\mathrm{s}}=0.43, p=0.003\right)$. No other statistically significant associations were found between COVID-19 related parental stress and clinically relevant variables (Supplementary Table S3).
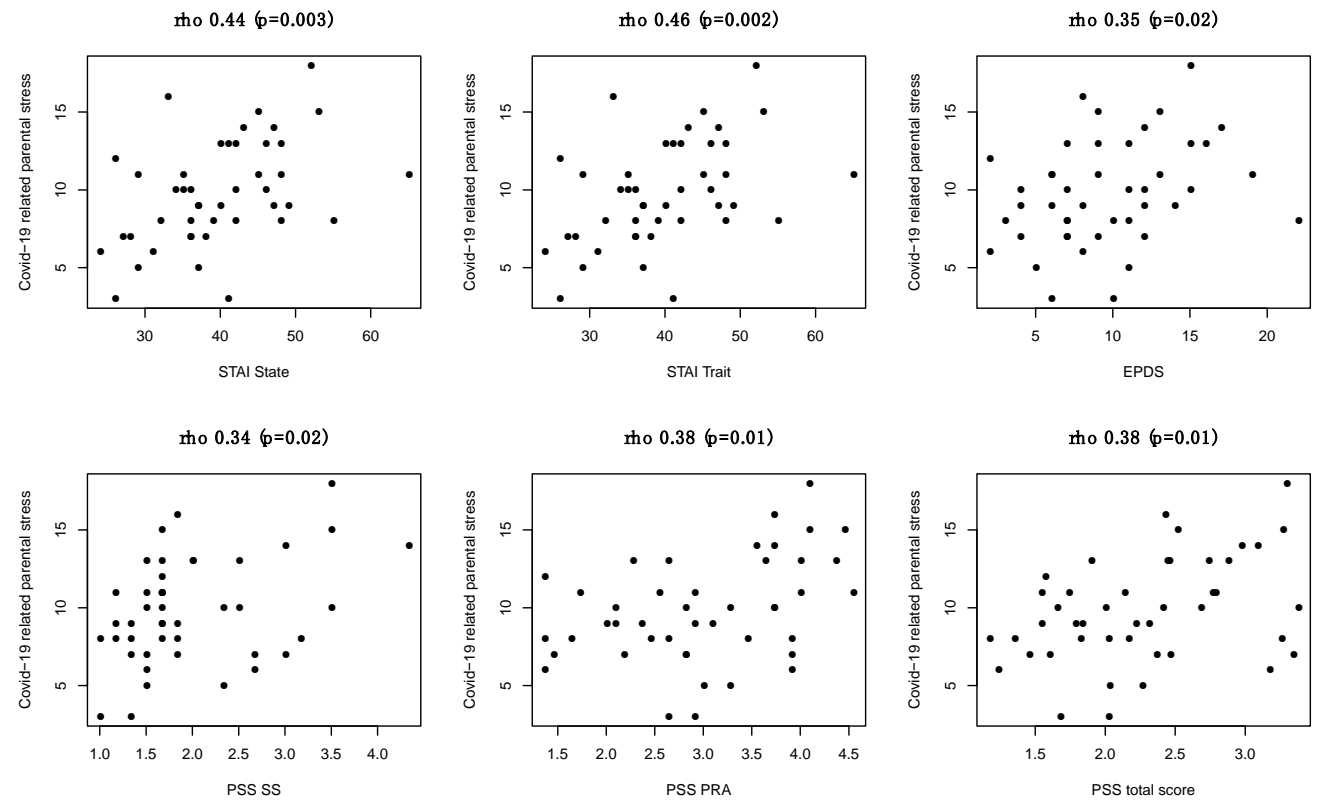

Figure 2. Association between COVID-19 related parental stress and STAI state, STAI trait, EPDS, PSS-SS, PSS-PRA and PSS-total score. 
Of note, the STAI trait was higher in parents who reported a negative impact of the COVID-19 pandemic on becoming a parent due to (i) less physical contact with the infant because of the preventive measures $(p=0.03)$ and (ii) concerns about the infant's health $(p=0.04)$ (Figure 3). The association between the main COVID-19 related factors having a negative impact on becoming a parent and the STAI trait and EPDS is reported in Supplementary Table S4.

Less physicalcontact w the in fant $(p=0.03)$

Concerns about in fan thealth $(p=0.04)$
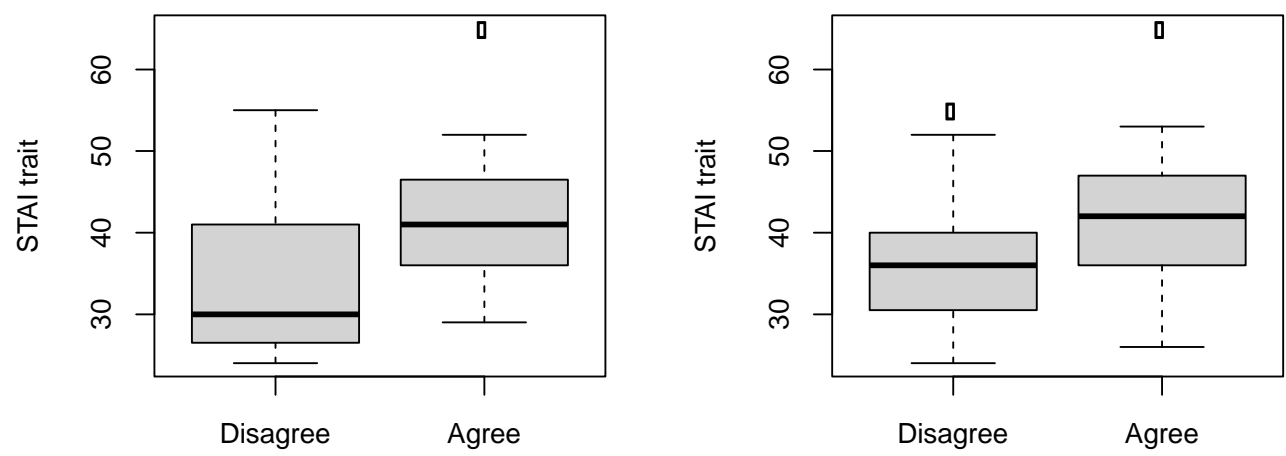

Figure 3. STAI trait in parents who reported a negative impact of the COVID-19 pandemic on becoming a parent due to less physical contact with the infant because of the preventive measures, and those who reported a negative impact of the COVID-19 pandemic on becoming a parent due to concerns about the infant's health.

A sub-analysis was performed in the 19 mother-father pairs (Supplementary Table S5). The median number of visits to the infant in the NICU was seven (IQR 5-12) among mothers and six (IQR 4-13) among fathers $(p=0.81)$. EPDS, PSS-IBA and PSS-PRA were higher in mothers than in fathers ( $p=0.02, p=0.01$ and $p=0.02$, respectively), while no statistically significant differences were found in COVID-19 related parental stress, STAI and PSS-SS (Figure 4). In addition, the PSS-total score was higher in mothers than in fathers $(p=0.01$, Supplementary Table S5).
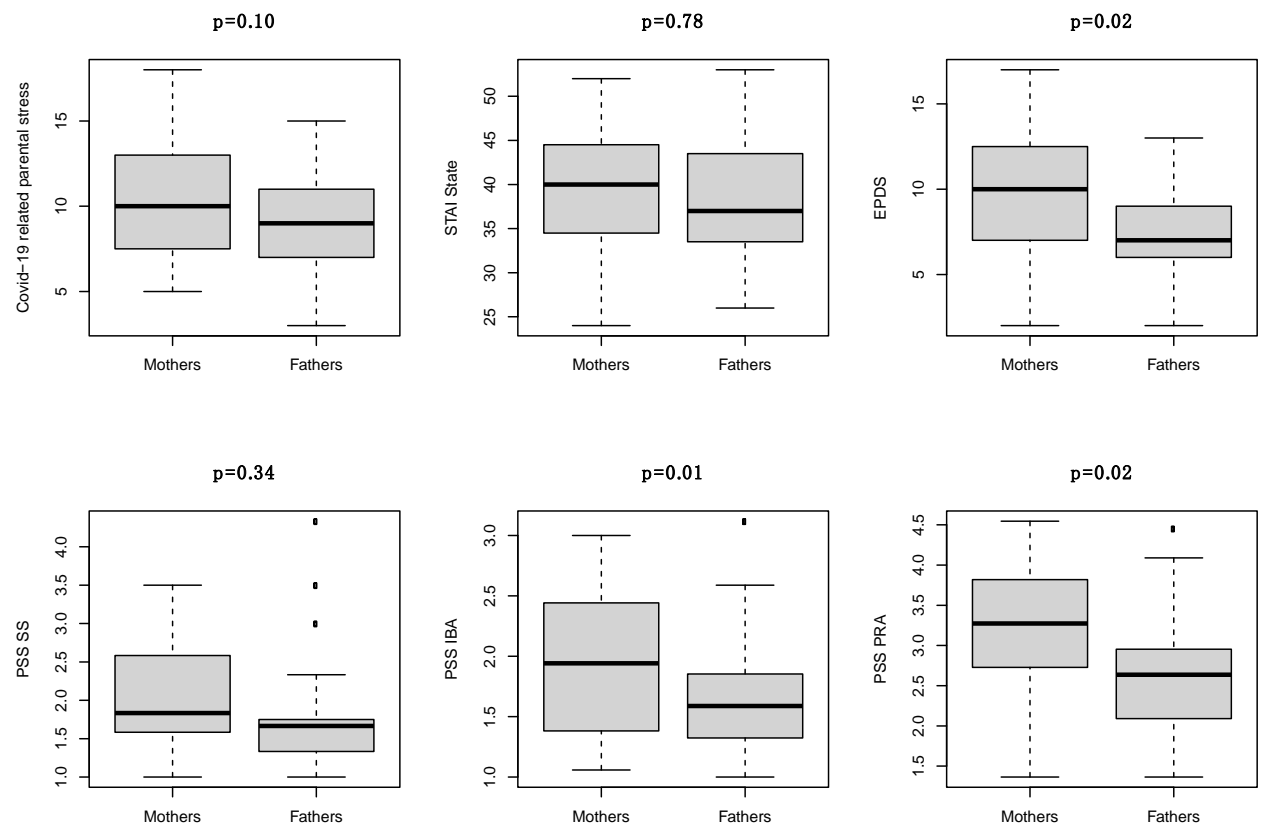

Figure 4. Comparison of COVID-19 related parental stress, STAI State, EPDS, PSS-SS, PSS-IBA and PSS-PRA between fathers and mothers of the same child. 


\section{Discussion}

This study aimed to investigate the psychological wellbeing of mothers and fathers with infants admitted to the NICU during the COVID-19 pandemic.

Results showed that more than half of parents scored over the cut-off for anxiety and almost one quarter scored over the cut-off for risk of depression. This is consistent with previous studies showing high levels of depression and anxiety among NICU families $[2,17,19]$. About one third of parents reported extreme/high stress and a relevant negative impact on the experience of becoming parents specifically due to the pandemic. Most parents reported restrictions on time and physical contact with their infant due to preventive measures as main factors that negatively impacted their experience of parenthood, alongside additional concerns for their child's health. Limited social support from family and friends and concerns about the health of loved ones due to pandemic were other frequent responses. Interestingly, some parents spontaneously reported the inability to share visits to the child in the NICU with the partner as a further stress source.

We can observe a strong relational as well as emotional connotation in the parental stress emerging from this study. Prolonged separation from the newborn interferes with the parent/child relationship, a fundamental and neurobiologically founded factor for infant development and health $[2,6]$. The need of closeness, contact and interaction between parent and child is rooted in instincts programmed by evolution for the safety of the mammalian offspring, and separation may induce distress and fear in both [2,6]. During the pandemic, parental visits in NICU are limited and nurturing experiences including breastfeeding, kangaroo care, or parents' talking with their infant, which are routinely employed to mitigate stress, are less frequent or not feasible $[3,12,13]$. Moreover, the inability to share NICU visits with the partner prevents parental mutual support that is an essential resource for emotional adaptation to such a distressing experience [13]. Additionally, limited social support and social isolation due to pandemic restrictions may reduce parents' resources for coping with stress and anxiety [28-30].

Results showed that parental COVID-19 related stress was positively and significantly associated with STAI scores, EPDS score, PSS-total score, PSS-SS and PSS-PRA subscales, and PSS-perceived stress items. Although the cross-sectional design does not allow determining causal relationships between variables, we can observe that parents with higher the COVID-19 stress were individuals with a higher proneness to experience anxiety. People with higher anxiety traits tend to view the world as more threatening and to respond more frequently with state anxiety to situations [22,31]. During the NICU stay, the unfamiliar environment and the adverse medical conditions of the children prevent parents from immediately taking care of them and this may lead to them experiencing a higher level of stress, mostly because of parental role marginalization [17,18,23,32], as also found in the present study. Parents live in a state of physical and psychological separation from their babies feeling powerless, stressed and vulnerable to emotional difficulties [17-19]. The sense of powerlessness and alienation can alter parental roles and self-image, further increase negative feelings such as anxiety, depression and anger, and consequently, affect the early bond with the child $[1,17-19,23,32,33]$.

This situation is undoubtedly worsened by additional pandemic worries and restrictions that limit parents/infants interactions and interfere with parental bonding and caregiving $[3,12,13]$. In our sample, anxiety was higher in parents who reported a negative impact of the COVID-19 pandemic on parenthood due to less physical contact with the child and additional concerns about the infant's health due to the pandemic. Recent studies showed that concerns about COVID-19, combined with social limitations due to preventive measures, adversely affected thoughts and emotions of new mothers of full term babies, incrementing mental health symptoms such as anxiety, depression and distress [28-30]. Most mothers of normal newborn nursery and NICU infants reported a negative impact of the pandemic on social and family relationships, maternal role and stress, with higher degree of helplessness among mothers of NICU infants [34]. Of note, data about fathers were not available in the literature. 
When comparing the psychological status of mothers and fathers, we found no differences relating to factors more linked to the context such as COVID-19 related parental stress, STAI state and PSS-SS. This suggests that parents were similarly impacted by the situation, be it the pandemic or the NICU environment. Instead, mothers and fathers showed differences in variables more related to their specific experience of parenthood such as EPDS, PSS-total score, PSS-IBA and PSS-PRA. Significantly higher scores in mothers were in line with previous studies indicating differences in parental vulnerability immediately after preterm birth $[2,17,18]$. In new mothers, physiological postpartum processes and hormones could affect mood and susceptibility to stress [35]. Furthermore, preterm births are often the unexpected results of mothers' medical complications that require immediate interruption of the pregnancies to prevent serious threats to the babies and mothers' health $[17,18]$. Hence, mothers' higher EPDS score and PSS-total score could also be linked to a post-traumatic state [2,17-19].

Higher PSS-IBA and PSS-PRA could be explained within the framework of the "primary maternal preoccupation" [36]. It is a physiological, biologically determined special state of enhanced sensitivity that heightens parents' abilities to anticipate the infant's needs and signals, and constitutes a fundamental stage for the parent/infant relationship and the later infant's cognitive, emotional and relational development $[32,35,36]$ It develops toward the end of pregnancy and lasts for the first postnatal weeks/months. Although parents displayed a similar time course, the degree of preoccupation is significantly higher for mothers [36]. From a biological and evolutionary perspective, not being allowed or able to protect and take maternal responsibility for the infant is expected to cause emotional distress $[2,32,36,37]$.

Despite the small sample, which represents the main limitation of this study, findings offer a first overview of the psychological wellbeing of parents of children admitted to the NICU during the pandemic. Of note, screening of the psychological wellbeing of parents was not performed before the pandemic at our institution (except for extremely few cases with mental disorders), thus comparisons with historical data were not possible.

As a consequence of the findings of this study, our institution strengthened the psychological support to parents of infants in the NICU and relaxed the restrictions on parental visits by increasing the time and the number of visits per day.

It is important to pay close attention to parents' emotional experiences in the NICU, particularly in the context of this pandemic, since the first moments after delivery, and offer proper support especially to more vulnerable parents in order to ensure family wellbeing and prevent future problems [19]. As stress in the NICU is critical not only for parents mental health, but also due to potential implications for their relationship with their infant and subsequent child development, strategies are needed to mitigate it in order to optimize child health and family resilience during this incomparable period [3,12,13]. Parents' presence in the NICU, their involvement in newborn care and the unique relationship with their baby are fundamental for infant health and neurobehavioral development as well as for parents' wellbeing. Such aspects may be taken into consideration when limitations to visits are planned. Should restrictions be needed again in the future, adequate psychological support for parents should be provided, to respond effectively to their expected suffering $[11,13,14]$. Using telemedicine in an effective and equitable manner has been also recommended [12,14]. A recent study showed that video messages sent from neonatal staff to families improve parental experience and involvement, and may mitigate the effects of family separation, including during restrictions associated with COVID-19 [38].

\section{Conclusions}

The pandemic seems to affect parental wellbeing both directly and indirectly. Direct effects consist of the additional stress due to the risk of contagion and COVID-19 related concerns. Indirect effects refer to the impact of health policies and restrictions on the 
experience of becoming parents. The ability to deal with such a challenging situation depends on individual characteristics, resources and environmental facilitations.

Supplementary Materials: The following are available online at https:/ /www.mdpi.com/article/10 .3390 / children8090755/s1, Table S1: Ad-hoc questionnaire developed to assess the COVID-19 related parental stress, Table S2: COVID-19 related parental stress, Table S3: Factors associated with overall score on COVID-19 related parental stress, Table S4: Association between the main COVID-19 related factors having a negative impact on becoming parent and STAI trait and EPDS, Table S5: Comparison of mother-father pairs.

Author Contributions: L.P. contributed to study design, data collection and interpretation, and writing of the draft of the manuscript. F.C. was responsible for the statistical design and analysis, data interpretation, and writing of the manuscript. E.L. contributed to study design, coordinated and supervised data collection, and critically reviewed the manuscript. R.S. contributed to study design, supervised data collection, data interpretation, and critically reviewed the manuscript. M.B. contributed to study design, data interpretation, and critically reviewed the manuscript. B.V. contributed to study design, data interpretation, and critically reviewed the manuscript. M.M. contributed to study design, coordinated data collection, and critically reviewed the manuscript. E.B. contributed to study design, data interpretation, and critically reviewed the manuscript. D.T. conceived the study, contributed to study design, data interpretation, and writing of the manuscript. All authors have read and agreed to the published version of the manuscript.

Funding: This research received no external funding.

Institutional Review Board Statement: The study was conducted according to the guidelines of the Declaration of Helsinki, and approved by the Padua University Hospital Ethics Committee (protocol number 0014664).

Informed Consent Statement: Informed consent was obtained from all subjects involved in the study.

Data Availability Statement: Further data are available from the corresponding author, upon reasonable request.

Acknowledgments: We thank Giulia Dal Pos, Debora De Grandis, Veronica Parigiani and Roberta Zonta for their help in data collection. We are very grateful to the parents who participated in the study.

Conflicts of Interest: The authors have no competing interests relevant to this article to disclose.

\section{References}

1. Roque, A.T.F.; Lasiuk, G.C.; Radünz, V.; Hegadoren, K. Scoping Review of the Mental Health of Parents of Infants in the NICU. JOGNN J. Obstet. Gynecol. Neonatal Nurs. 2017, 46, 576-587. [CrossRef]

2. Tandberg, B.S.; Flacking, R.; Markestad, T.; Grundt, H.; Moen, A. Parent psychological wellbeing in a single-family room versus an open bay neonatal intensive care unit. PLOS ONE 2019, 14, e0224488.

3. Erdei, C.; Liu, C.H. The downstream effects of COVID-19: A call for supporting family wellbeing in the NICU. J. Perinatol. 2020, 40, 1283-1285. [CrossRef]

4. Rogers, C.E.; Kidokoro, H.; Wallendorf, M.; Inder, T.E. Identifying mothers of very preterm infants at-risk for postpartum depression and anxiety before discharge. J. Perinatol. 2013, 33, 171-176. [CrossRef]

5. Treyvaud, K.; Lee, K.J.; Doyle, L.W.; Anderson, P.J. Very preterm birth influences parental mental health and family outcomes seven years after birth. J. Pediatr. 2014, 164, 515-521. [CrossRef]

6. Bergman, N.J.; Ludwig, R.J.; Westrup, B.; Welch, M.G. Nurturescience versus neuroscience: A case for rethinking perinatal mother-infant behaviors and relationship. Birth Defects Res. 2019, 111, 1110-1127. [CrossRef]

7. McManus, B.M.; Poehlmann, J. Parent-child interaction, maternal depressive symptoms and preterm infant cognitive function. Infant Behav. Dev. 2012, 35, 489-498. [CrossRef]

8. Turpin, H.; Urben, S.; Ansermet, F.; Borghini, A.; Murray, M.M.; Müller-Nix, C. The interplay between prematurity, maternal stress and children's intelligence quotient at age 11: A longitudinal study. Sci. Rep. 2019, 9, 1-9. [CrossRef]

9. Huhtala, M.; Korja, R.; Lehtonen, L.; Haataja, L.; Lapinleimu, H.; Rautava, P.; PIPARI Study Group. Associations between parental psychological well-being and socio-emotional development in 5-year-old preterm children. Early Hum. Dev. 2014, 90, 119-124. [CrossRef]

10. Hall, S.L.; Cross, J.; Selix, N.W.; Patterson, C.; Segre, L.; Chuffo-Siewert, R.; Geller, P.A.; Martin, M.L. Recommendations for enhancing psychosocial support of NICU parents through staff education and support. J. Perinatol. 2015, 35, S29-S36. [CrossRef] [PubMed] 
11. Treyvaud, K.; Spittle, A.; Anderson, P.J.; O’Brien, K. A multilayered approach is needed in the NICU to support parents after the preterm birth of their infant. Early Hum. Dev. 2019, 139, 104838. [CrossRef]

12. Murray, P.D.; Swanson, J.R. Visitation restrictions: Is it right and how do we support families in the NICU during COVID-19? J. Perinatol. 2020, 40, 1576-1581. [CrossRef]

13. Bembich, S.; Tripani, A.; Mastromarino, S.; di Risio, G.; Castelpietra, E.; Risso, F.M. Parents experiencing NICU visit restrictions due to COVID-19 pandemic. Acta Paediatr. Int. J. Paediatr. 2020. [CrossRef]

14. Carter, B.S.; Willis, T.; Knackstedt, A. Neonatal family-centered care in a pandemic. J. Perinatol. 2021, 41, 1177-1179. [CrossRef]

15. SIN-Società Italiana di Neonatologia. 2021. Available online: https:/ / www.sin-neonatologia.it (accessed on 25 August 2021).

16. COVID-19-EFCNI. [Online]. Available online: https://www.efcni.org/health-topics/covid-19-faq/ (accessed on 25 August 2021).

17. Ionio, C.; Colombo, C.; Brazzoduro, V.; Mascheroni, E.; Confalonieri, E.; Castoldi, F.; Lista, G. Mothers and fathers in nicu: The impact of preterm birth on parental distress. Eur. J. Psychol. 2016, 12, 604-621. [CrossRef]

18. Ionio, C.; Mascheroni, E.; Colombo, C.; Castoldi, F.; Lista, G. Stress and feelings in mothers and fathers in NICU: Identifying risk factors for early interventions. Prim. Heal. Care Res. Dev. 2019, 20, 1-7. [CrossRef]

19. Trumello, C.; Candelori, C.; Cofini, M.; Cimino, S.; Cerniglia, L.; Paciello, M.; Babore, A. Mothers' depression, anxiety, and mental representations after preterm birth: A study during the infant's hospitalization in a neonatal intensive care unit. Front. Public Health 2018, 6, 359. [CrossRef] [PubMed]

20. Carpiniello, B.; Pariante, C.M.; Serri, F.; Costa, G.; Carta, M.G. Validation of the Edinburgh postnatal depression scale in Italy. J. Psychosom. Obstet. Gynaecol. 1997, 18, 280-285. [CrossRef] [PubMed]

21. Cox, J.L.; Holden, J.M.; Sagovsky, R. Detection of Postnatal Depression: Development of the 10-item Edinburgh Postnatal Depression scale. Br. J. Psychiatry 1987, 150, 782-786. [CrossRef] [PubMed]

22. Spielberger, C.D. Manual for the State-Trait Anxiety Inventory (STAI Form Y); Consulting Psycologists Press: Palo Alto, CA, USA, 1983.

23. Montirosso, R.; Provenzi, L.; Calciolari, G.; Borgatti, R. Measuring maternal stress and perceived support in 25 Italian NICUs. Acta Paediatr. Int. J. Paediatr. 2012, 101, 136-142. [CrossRef]

24. Carter, M.C.; Miles, M.S. The Parental Stressor Scale: Pediatric Intensive Care Unit. Matern. Child. Nurs. J. 1989, 18, 187-198.

25. Vanaken, L.; Scheveneels, S.; Belmans, E.; Hermans, D. Validation of the Impact of Event Scale With Modifications for COVID-19 (IES-COVID19). Front. Psychiatry 2020, 11, 738. [CrossRef] [PubMed]

26. Ostacoli, L.; Cosma, S.; Bevilacqua, F.; Berchialla, P.; Bovetti, M.; Carosso, A.R.; Malandrone, F.; Carletto, S.; Benedetto, C. Psychosocial factors associated with postpartum psychological distress during the COVID-19 pandemic: A cross-sectional study. BMC Pregnancy Childbirth 2020, 20, 703. [CrossRef] [PubMed]

27. R Core Team. A Language and Environment for Statistical Computing; R Foundation for Statistical Computing: Vienna, Austria, 2020.

28. Zanardo, V.; Manghina, V.; Giliberti, L.; Vettore, M.; Severino, L.; Straface, G. Psychological impact of COVID-19 quarantine measures in northeastern Italy on mothers in the immediate postpartum period. Int. J. Gynecol. Obstet. 2020, 150, 184-188. [CrossRef]

29. Yan, H.; Ding, Y.; Guo, W. Mental Health of Pregnant and Postpartum Women During the Coronavirus Disease 2019 Pandemic: A Systematic Review and Meta-Analysis. Front. Psychol. 2020, 11, 3324. [CrossRef]

30. Liu, C.H.; Erdei, C.; Mittal, L. Risk factors for depression, anxiety, and PTSD symptoms in perinatal women during the COVID-19 Pandemic. Psychiatry Res. 2021, 295, 113552. [CrossRef]

31. Leal, P.C.; Goes, T.C.; da Silva, L.C.F.; Teixeira-Silva, F. Trait vs. state anxiety in different threatening situations. Trends Psychiatry Psychother. 2017, 39, 147-157. [CrossRef] [PubMed]

32. Ionio, C.; Lista, G.; Mascheroni, E.; Olivari, M.G.; Confalonieri, E.; Mastrangelo, M.; Brazzoduro, V.; Balestriero, M.A.; Banfi, A.; Bonanomi, A.; et al. Premature birth: Complexities and difficulties in building the mother-child relationship. J. Reprod. Infant Psychol. 2017, 35, 509-523. [CrossRef]

33. Alkozei, A.; McMahon, E.; Lahav, A. Stress levels and depressive symptoms in NICU mothers in the early postpartum period. J. Matern. Neonatal Med. 2014, 27, 1738-1743. [CrossRef]

34. Bin-Nun, A.; Palmor-Haspal, S.; Mimouni, F.B.; Kasirer, Y.; Hammerman, C.; Tuval-Moshiach, R. Infant delivery and maternal stress during the COVID-19 pandemic: A comparison of the well-baby versus neonatal intensive care environments. J. Perinatol. 2021, 2021, 1-7.

35. Schiller, C.E.; Meltzer-Brody, S.; Rubinow, D.R. The role of reproductive hormones in postpartum depression. CNS Spectr. 2015, 20, 48-59. [CrossRef] [PubMed]

36. Leckman, J.F.; Feldman, R.; Swain, J.E.; Eicher, V.; Thompson, N.; Mayes, L.C. Primary parental preoccupation: Circuits, genes, and the crucial role of the environment. J. Neural Transm. 2004, 111, 753-771. [CrossRef] [PubMed]

37. Garrison, A.M.; Kahn, J.H.; Sauer, E.M.; Florczak, M.A. Disentangling the effects of depression symptoms and adult attachment on emotional disclosure. J. Couns. Psychol. 2012, 59, 230-239. [CrossRef]

38. Kirolos, S.; Sutcliffe, L.; Clausen, M.G.; Abernethy, C.; Shanmugalingam, S.; Bauwens, N.; Orme, J.; Thomson, K.; Grattan, R.; Patel, N. Asynchronous video messaging promotes family involvement and mitigates separation in neonatal care. Arch. Dis. Childhood-Fetal Neonatal Ed. 2021, 106, 172-177. [CrossRef] [PubMed] 